\title{
Cell-Type-Specific Changes in Intrinsic Excitability in the Subiculum following Learning and Exposure to Novel Environmental Contexts
}

\author{
(1D)Amy R. Dunn, ${ }^{\wedge}$ (1) Sarah M. Neuner, ${ }^{1,2^{\wedge}}$ Shengyuan Ding, ${ }^{1,2}$ Kevin A. Hope, ${ }^{2}$ Kristen M.S. O'Connell, ${ }^{1,2}$ \\ and Catherine C. Kaczorowski ${ }^{1,2}$
}

https://doi.org/10.1523/ENEURO.0484-18.2018

${ }^{1}$ The Jackson Laboratory, Bar Harbor, ME 04609 and ${ }^{2}$ University of Tennessee Health Sciences Center, Memphis, TN 38136

\begin{abstract}
The subiculum is the main target of the hippocampal region CA1 and is the principle output region of the hippocampus. The subiculum is critical to learning and memory, although it has been relatively understudied. There are two functional types of principle neurons within the subiculum: regular spiking (RS) and burst spiking (BS) neurons. To determine whether these cell types are differentially modified by learning-related experience, we performed whole-cell patch clamp recordings from male mouse brain slices following contextual fear conditioning (FC) and memory retrieval relative to a number of control behavioral paradigms. RS cells, but not BS cells, displayed a greater degree of experience-related plasticity in intrinsic excitability measures [afterhyperpolarization (AHP), input resistance $\left(R_{\text {input }}\right)$, current required to elicit a spike], with fear conditioned animals having generally more excitable RS cells compared to naïve controls. Furthermore, we found that the relative proportion of RS to BS neurons is modified by the type of exposure, with the lowest proportion of BS subicular cells occurring in animals that underwent contextual FC followed by a retrieval test. These studies indicate that pyramidal neurons in the subiculum undergo experience- and learning-related plasticity in intrinsic properties in a cell-type-specific manner. As BS and RS cells are thought to convey distinct types of information, this plasticity may be particularly important in encoding, consolidating, and recalling spatial information by modulating information flow from the hippocampus to cortical regions.
\end{abstract}

Key words: burst spiking; contextual fear conditioning; intrinsic excitability; plasticity; regular spiking; subiculum

\section{Significance Statement}

The subiculum is the main output region of the hippocampus and contains two main neuron types: regular spiking (RS) and burst spiking (BS). Here, we show that learning and novel context exposure induces plasticity in intrinsic excitability in RS cells of the subiculum and that this plasticity predicts degree of learning of contextual fear conditioning (FC). In contrast, we observed no significant learning-induced plasticity in intrinsic properties in subicular BS cells; however, we did observe an apparent conversion of BS to RS as evidenced by a greater proportion of RS neurons within the subiculum following learning. This suggests that the ratio of RS to BS neurons within the subiculum, together with enhanced excitability of RS neurons, is important in learning and memory.

\section{Introduction}

The subiculum plays a pivotal role in conveying information from the hippocampus to cortical and subcortical

Received December 11, 2018; accepted December 12, 2018; First published December 26, 2018.

The authors declare no competing financial interests. regions, receiving and integrating information directly from hippocampal region CA1 (Naber and Witter, 1998). The subiculum mediates various aspects of behavior in- 
cluding spatial and declarative memory, contextual fear memory, memory retrieval, discrimination of complex scenes, temporal control of behavior, and motivated behavior (Gabrieli et al., 1997; Maren, 1999; O’Mara et al., 2009; Hodgetts et al., 2017; Roy et al., 2017; Cembrowski et al., 2018). In humans, it is involved in both normal cognitive function and in diseases characterized by impaired cognition including schizophrenia and Alzheimer's disease (Carlesimo et al., 2015; Haukvik et al., 2015; Lindberg et al., 2017; Zammit et al., 2017). The subiculum is organized in both proximal-distal and dorsal-ventral directions, with heterogenous inputs and outputs, cell types, cytoarchitecture, contributions to behavior, and gene and protein expression along each axis (O'Mara, 2005; O'Mara et al., 2009; Kim and Spruston, 2012; Honda and Ishizuka, 2015; Ishihara and Fukuda, 2016; Tang et al., 2016; Roy et al., 2017; Cembrowski et al., 2018). This complex organization likely allows for various parallel information processing pathways flowing from the hippocampus.

The subiculum has two pyramidal neuron types, burst spiking (BS) and regular spiking (RS) cells. Previous studies indicate that BS cells make up about one-half of pyramidal neurons in the subiculum. BS cells are not evenly distributed throughout the subiculum (Staff et al., 2000), with the density of BS cells gradually increasing along the proximal-distal axis (Jarsky et al., 2008). RS and BS cells show differences in synaptic plasticity (Wozny et al., 2008; Behr et al., 2009; Shor et al., 2009; Graves et al., 2016), as well as differences in intrinsic excitability (Staff et al., 2000; Behr et al., 2009). The differences in plasticity, pathways, and excitability of these cell types suggest meaningful differences in how and what information is encoded by BS and RS cells, allowing the subiculum to regulate learning- and memory-related information conveyance from the hippocampus to the rest of the brain.

Plasticity in intrinsic excitability is an important mechanism of learning and memory (Titley et al., 2017) and arises from changes to ion channel function and/or distribution on the surface of neuronal membranes. Changes in intrinsic excitability may occur independently of synaptic plasticity, but can also modulate synaptic plasticity (Sehgal et al., 2013). The relationship between learning and intrinsic properties of neurons has been extensively studied throughout the brain, including CA1, the amygdala (Sehgal et al., 2014), and the cortex (Song et al., 2015; Soler-Cedeño et al., 2016). Learning and environmental

This work was supported by the NIH Grant R01AG054180 (to C.C.K.), the NIH Grant R21AG048446 (to C.C.K.), the Evnin Family (C.C.K.), the Alzheimer's Association Grant AARF 18-565506 (to A.R.D.), and the NIH Grant F31AG050357 (to S.M.N.)

${ }^{\wedge}$ A.R.D. and S.M.N. contributed equally to this work.

Correspondence should be addressed to Catherine C. Kaczorowski, The Jackson Laboratory, 600 Main Street, Bar Harbor, ME 04609, E-mail: catherine.kaczorowski@jax.org.

https://doi.org/10.1523/ENEURO.0484-18.2018

Copyright @ 2018 Dunn et al.

This is an open-access article distributed under the terms of the Creative Commons Attribution 4.0 International license, which permits unrestricted use, distribution and reproduction in any medium provided that the original work is properly attributed. enrichment generally result in greater neuronal excitability across species (Kumar and Foster, 2007; Oh et al., 2009; Matthews et al., 2009; Song et al., 2012), and enhanced intrinsic excitability as measured by a reduced afterhyperpolarization (AHP) is associated with better learning and memory (Kaczorowski and Disterhoft, 2009). However, it is unknown how learning alters intrinsic excitability of subicular neurons. Given the diversity in subicular pyramidal neurons, and their importance in integrating and transmitting information from the hippocampus, determining how learning remodels the subiculum is critical to a more complete understanding of how learning and memory is encoded in the brain.

Here, we examined how hippocampal-dependent contextual fear conditioning (FC; Phillips and LeDoux, 1992) modifies intrinsic excitability properties of subicular RS and BS cells. We observed enhanced excitability across various measures following learning compared to naïve animals, and these learning-related changes were specific to RS cells. Greater excitability in RS cells was associated with better performance on long-term contextual memory. Finally, we found that learning results in an increase in the proportion of RS cells, suggesting interconversion between BS and RS cells in vivo following context encoding and recall. Our study supports previous research demonstrating differential plasticity in RS and BS, and confirms that the subiculum undergoes cell-type-specific plasticity in intrinsic properties following novel context encoding and fear learning. Overall, we found that experiencedependent remodeling of RS cells may be important in generating new learning and contextual memory related information.

\section{Materials and Methods}

\section{Animals}

Adult male (seven to eight weeks) C57BL/6J were obtained from the live repository at The Jackson Laboratory (JAX; RRID:IMSR_JAX:000664) and housed on a 12/12 h light/dark cycle with ad libitum access to food and water. All experiments occurred at JAX or the University of Tennessee Health Science Center (UTHSC) and were conducted in accordance with the JAX and UTHSC Animal Care and Use Committee and the National Institutes of Health Guide for the Care and Use of Laboratory Animals.

\section{Behavioral paradigms}

Animals were randomly assigned to behavioral paradigms (Fig. $1 A$, schematic), and underwent the following behavioral testing.

\section{Contextual FC}

Animals were habituated to the behavioral testing facility for at least $3 \mathrm{~d}$ before training. Specifically, animals were transported in their home cages to a holding room separated from the testing room for $1 \mathrm{~h} / \mathrm{d}$ before testing. Because mice were group-housed within their home cages and only one animal per day was tested, cagemates awaiting testing were necessarily habituated for additional days (up to 10 additional days). Mice were trained on a standard contextual FC paradigm as described previously (Neuner et al., 2015). Briefly, animals 
A
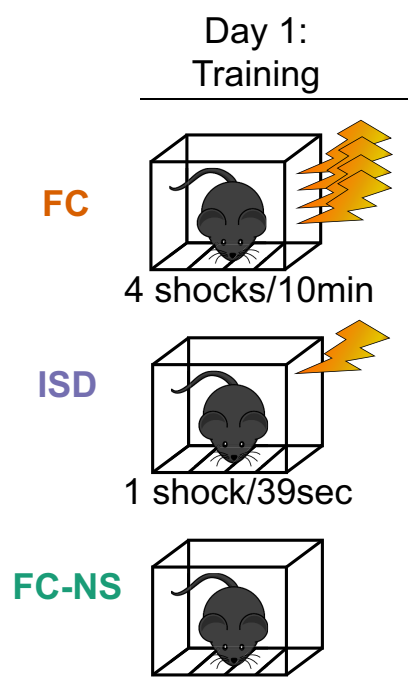

No shock/10min

ISD-NS

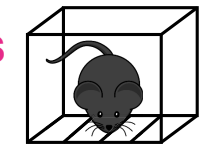

No shock/39sec
Day 2: Testing

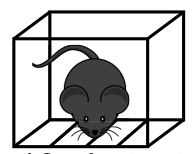

$10 \mathrm{~min}$ test
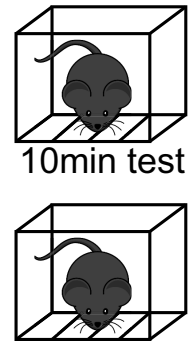

10 min test

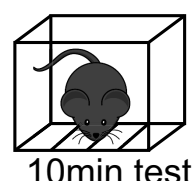

B
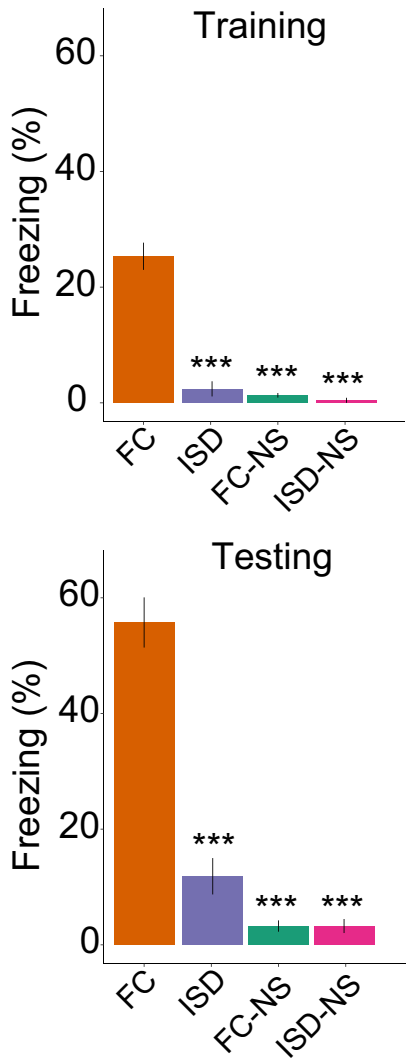

Figure 1. Contextual FC results in greater fear memory compared to control groups. $\boldsymbol{A}$, Animals were randomly assigned to one of several behavioral training paradigms including: FC, ISD, FC-NS, and ISD-NS. $\boldsymbol{B}$, Degree of freezing during training and during the testing period the following day were assessed. Animals in the FC condition froze significantly more than any other group on both training and testing days, as expected; $* * * p<0.001$.

were placed in the conditioning chambers. Following a 150 -s baseline period, animals received four mild foot shocks ( $1 \mathrm{~s}, 0.9 \mathrm{~mA}$ ) separated by $150 \pm 25 \mathrm{~s}$ over $10 \mathrm{~min}$. The $20 \mathrm{~s}$ following each shock was designated as the postshock period, and freezing during each postshock period was quantified. Twenty-four hours later, animals were returned to the chambers for $10 \mathrm{~min}$. Percentage time spent freezing during this time was measured using FreezeFrame software (ActiMetrics; RRID:SCR_014429) and used as an index of long-term contextual memory, consolidation and retrieval. Immediately after testing, animals were anaesthetized using isoflurane and hippocampal slices harvested for electrophysiological analysis.

\section{Immediate shock deficit (ISD)}

Animals were habituated to the behavioral testing facility for at least $3 \mathrm{~d}$ before training. Animals were placed in the conditioning chamber, immediately received a mild foot shock ( $4 \mathrm{~s}, 0.9 \mathrm{~mA})$, and were rapidly removed from the chamber, for a total of $39 \mathrm{~s}$ spent in the conditioning chamber. Twenty-four hours later, animals returned to the chambers for $10 \mathrm{~min}$. Immediately following testing, animals were anaesthetized using isoflurane and hippocampal slices harvested for electrophysiological analysis. This provided a control for exposure to the stress of receiving foot shocks for 4-s total in experimental groups (Neuner et al., 2015).

\section{FC-no shock (FC-NS) control}

Animals were habituated to the behavioral testing facility for at least $3 \mathrm{~d}$ before training. Animals were allowed to explore the conditioning chamber for $10 \mathrm{~min}$ with no foot shock. Twenty-four hours after "training," animals were again allowed to explore the conditioning chambers for 10 min. Immediately after testing, animals were anaesthetized using isoflurane and hippocampal slices harvested for electrophysiological analysis. This provided a noshock control to the FC group.

\section{ISD-no shock (ISD-NS) control}

Animals were habituated to the behavioral testing facility for at least $3 \mathrm{~d}$ before training. Animals were placed in the FC chambers for $39 \mathrm{~s}$ with no shock, and returned to the chambers $24 \mathrm{~h}$ later for $10 \mathrm{~min}$. This provided a no-shock control for the ISD group. Immediately after testing, animals were anaesthetized using isoflurane and hippocampal slices harvested for electrophysiological analysis.

Naïve

Animals remained in the housing facility for the duration of the experiment and were removed only for electrophysiological analysis.

\section{Electrophysiology}

Hippocampal slices were prepared and whole-cell patch clamp recordings were performed from subicular 
neurons as described previously (Graves et al., 2016). Mice were deeply anaesthetized with isoflurane and decapitated. Brains were removed and placed in ice-cold artificial CSF (aCSF; $125 \mathrm{mM} \mathrm{NaCl}, 25 \mathrm{mM}$ glucose, 25 $\mathrm{mM} \mathrm{NaHCO}_{3}, 2.5 \mathrm{mM} \mathrm{KCl}, 1.25 \mathrm{mM} \mathrm{NaH}_{2} \mathrm{PO}_{4}, 2 \mathrm{mM}$ $\mathrm{CaCl}_{2}, 1 \mathrm{mM} \mathrm{MgCl}_{2}$, saturated with $\left.95 \% \mathrm{O}_{2} / 5 \% \mathrm{CO}_{2}\right) ; 300$ $\mu \mathrm{M}$ transverse sections were made with a vibratome (Leica, VT1000S). Slices were incubated in aCSF bubbled with $95 \% \mathrm{O}_{2} / 5 \% \mathrm{CO}_{2}$ at room temperature for at least 1 $\mathrm{h}$ before use. Slices were transferred to a recording chamber and continuously perfused with oxygenated aCSF at $\sim 30^{\circ} \mathrm{C}$. Synaptic blockers including 1-2 mM kynurenic acid (NMDA receptor antagonist, to block excitatory input) and $2 \mu \mathrm{M}$ SR95531 (GABA-A receptor antagonist, to block inhibitory input) were included in aCSF in initial studies but discontinued when no statistically significant differences in the intrinsic properties was observed compared to aCSF alone, consistent with prior studies of burst plasticity using learning-relevant electrical stimulation (Moore et al., 2009; Graves et al., 2012). Whole-cell recordings were made in the subiculum from thin-walled capillary glass pipettes (Sutter Instrument Co, P-97 and $\mathrm{P}$-2000) filled with potassium gluconate based internal solution (115 mM K-gluconate, $20 \mathrm{mM} \mathrm{KCl,} 10 \mathrm{mM} \mathrm{Na-}$ phosphocreatine, $10 \mathrm{mM}$ HEPES, $2 \mathrm{mM}$ MgATP, and 0.3 $\mathrm{mM}$ NaGTP, pH adjusted to 7.3). Pyramidal neurons in the subiculum were visually identified with a Q-Imaging digital camera and DIC-IR microscopy. Data were acquired using a MultiClamp 700B amplifier, digitized and interfaced to PC running pClamp10.4 with Axon Digidata 1550B analog to digital converter. Current clamp experiments were conducted to determine whether the excitability of pyramidal neurons in the subiculum are modulated by FC training. For assessment of intrinsic excitability (AHP, $\mathrm{I}_{\text {thresh, }}$ etc.), neurons were held at $-67 \mathrm{mV}$ with current injection. Series resistance and capacitance were monitored and compensated for throughout the recording. Membrane potentials were not corrected for the liquid junction potential, which was estimated to be $-8 \mathrm{mV}$ (Kaczorowski et al., 2007). Up to four subiculum cells per slice were recorded. Because there is not a well-defined boundary between distal and proximal subiculum, and various neuronal properties vary across a gradient from the proximal subiculum (i.e., adjacent to CA1) and distal subiculum (i.e., adjacent to the presubiculum), cells were chosen at random equally across the proximal-distal length of the subiculum. This random sampling procedure within the subiculum of naïve rodents has consistently identified $\sim 50 \%$ BS cells by our lab and others (Staff et al., 2000; Jarsky et al., 2008; Graves et al., 2016).

\section{Neuronal classification}

The subiculum contains two functionally distinct principle cell types. to test the hypothesis that neurons in the subiculum undergo learning-related changes in excitability, and determine whether these changes depend on cell type, neurons were classified as RS or BS based on their response to a 2-ms current pulse at threshold. RS neurons fired a single action potential in response to injected current at threshold, whereas BS neurons fired two or more action potentials.

\section{Assessing neuronal excitability}

Resting membrane potential (RMP) was recorded within five minutes of patching each cell. Input resistance $\left(R_{\text {input }}\right)$ was calculated using Ohm's law and determined by fitting the slope of the IV plot from the membrane response to 1-s current injections in 10-pA steps (from -50 to $+50 \mathrm{pA}$ ) at steady-state (i.e., last $100 \mathrm{~ms}$ of trace). The current threshold $\left(I_{\text {thresh }}\right)$ was defined as the minimum current required to elicit an action potential during a 2-ms current injection. The post-burst AHP was triggered using 25 brief $(2 \mathrm{~ms})$ somatic current injection (1 nA) at $50 \mathrm{~Hz}$. Membrane properties including fast AHP (fAHP), medium AHP (mAHP), and slow AHP (sAHP) were assessed as previously described (Kaczorowski et al., 2007, 2011; Kaczorowski and Disterhoft, 2009; Neuner et al., 2015; Graves et al., 2016). Briefly, the mAHP was measured as the peak negative membrane potential relative to baseline and the SAHP was measured as the average negative membrane potential relative to baseline at 1-1.05 s after last brief current injection of protocol for triggering post-burst AHP. The fAHP was measured as the peak negative membrane potential following the action potential(s) in response to 2-ms current injection at threshold, relative to baseline. Repetitive firing was evoked by short (1-s) depolarizing current steps in 50-pA increments or by sustained (15 s) depolarizing current steps in 20-pA increments. The relationship between the firing frequency and injected current was plotted for each cell.

\section{Statistics}

Data were analyzed using SPSS Statistics (IBM; RRID: SCR_002865) or R and visualized in R (RRID:SCR_001905). Behavioral data were analyzed using one-way ANOVA to identify differences between behavioral paradigms on freezing. Electrophysiological data were analyzed using univariate ANOVA (RMP, $\mathrm{R}_{\text {input }}, \mathrm{I}_{\text {thresh }}, \mathrm{AHP}$ ) between behavioral paradigms and cell type unless otherwise indicated. To test for significant differences between groups, post hoc Bonferroni tests were applied and adjusted for multiple comparisons. Total spike data were non-normally distributed and, as such, underwent log transformation before analysis. Because behavioral and electrophysiological data were collected across two institutions, we (1) analyzed the results of behavioral training and testing and found no statistically significant effect of institution on any of the measures, and (2) included location of testing in the univariate ANOVA model and identified input resistance in BS as the only parameter that showed a significant interactive effect of recording location and behavioral treatment. Differences in intrinsic excitability between RS and BS cells in naïve animals were analyzed using independent samples $t$ test. Post hoc power estimates were completed using G*Power software [Dusseldorf, Germany (Faul et al., 2007); RRID:SCR_013726] to confirm sufficient statistical power to perform analyses. A summary of statistical tests performed is shown in Table 1; superscript letters throughout the results section indicate corresponding statistic in this table.

\section{Exclusions}

Cells with an RMP of $-58 \mathrm{mV}$ or higher were excluded from further recording. Cells were excluded for a lack of 
Table 1. Detailed statistics summary

\begin{tabular}{lll}
\hline & Figure & Comparison \\
a & $1 B$ & Training freezing \\
& & \\
b & $1 B$ & Test freezing \\
c & $2 A$ & RMP \\
& & \\
d & $2 B$ & $\mathrm{R}_{\text {input }}$ \\
e & $2 C$ & fAHP \\
& & Naïve-FC
\end{tabular}

Naïve-ISD

Naïve-ISD-NS

f $2 D \quad \mathrm{mAHP}$

Naïve-FC

Naïve-ISD

Naïve-FC-NS

$\begin{array}{lll}\mathrm{g} & 2 E & \mathrm{sAHP} \\ \mathrm{h} & 3 A & \mathrm{I}_{\text {thresh }} \\ \mathrm{i} & 3 B & 1-\mathrm{s} \text { current injection } \\ \mathrm{j} & 3 B & \\ & & \\ & & \\ & & \\ & & \end{array}$

Naïve-ISD

Naïve-FC-NS

Naïve-ISD-NS

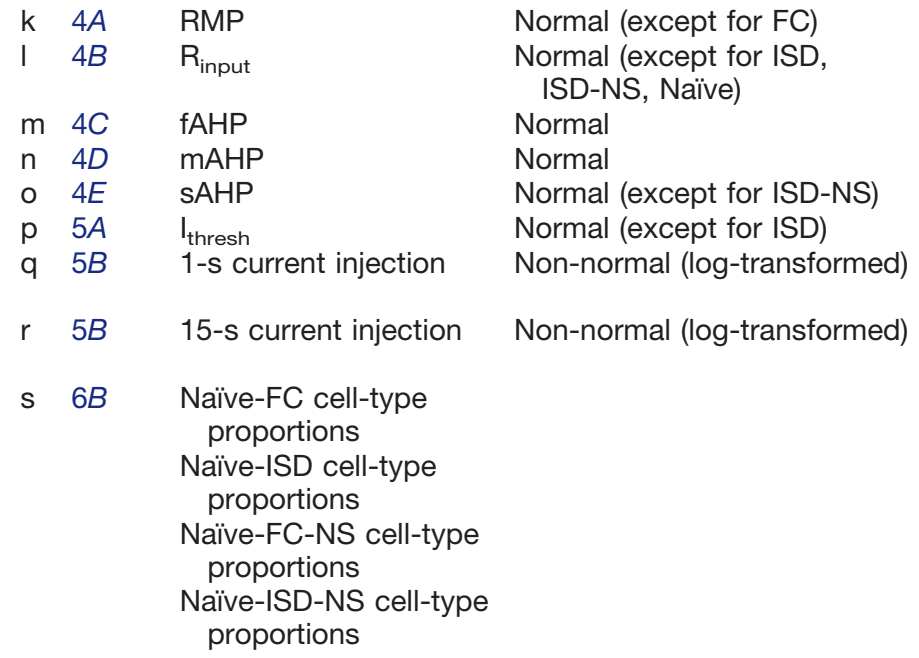

Data structure

Normal (except for FC-NS, ISD, ISD-NS)

Non-normal

Normal (except for FC-NS, ISD-NS)

Non-normal

Normal

Normal (except for FC, ISD)

Normal (except for ISD)

Normal (except for FC-NS, ISD)

Non-normal (log-transformed)

Non-normal (log-transformed)

One-way ANOVA

Repeated measures ANOVA

Repeated measures ANOVA

Post hoc (Bonferroni)

Post hoc (Bonferroni)

Post hoc (Bonferroni)

Post hoc (Bonferroni)

One-way ANOVA One-way ANOVA

One-way ANOVA

One-way ANOVA

One-way ANOVA

One-way ANOVA

Repeated measures

ANOVA

Repeated measures ANOVA

Marasculio procedure (repeated $\chi^{2}$ )

Type of test
One-way ANOVA df $=4, F=2.26$
$d f=4, F=1.567$
$d f=4, F=2.126$
df $=4, F=2.945$

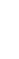

Statistic
Df $=3$,

$\mathrm{Df}=3, F=61.116 p<0.001$

Df $=4 ; F=1.737 \quad p=0.143$

$\mathrm{df}=4, F=2.099$

$\mathrm{df}=4, F=2.581$ $95 \% \mathrm{Cl}$

$p<0.001$

One-way ANOVA

$p=0.082$

$p=0.038$
Confidence,

$p=0.004$;

Cl: -1.00

to -0.12

$p=0.001$;

Cl: -1.09

to -0.18

$p=0.003$;

Cl: -1.03

to -0.14

$\mathrm{df}=4, F=2.433$

$p=0.049$

$p<0.000$;

Cl: -3.41

to -1.07

$p<0.000$;

Cl: -4.24

to -1.83

$p=0.015$;

Cl: -2.81

to -0.17

$p=0.064$

$p=0.18$

$p=0.079$

$p=0.021$

$p=0.30$

Cl: -0.75

to -0.02

$p=0.022$;

Cl: -0.79

to -0.03

$p=0.20$;

Cl: -0.88

to -0.04

$p=0.035$;

Cl: -0.75

to -0.02

$\mathrm{df}=4, F=1.166 \quad p=0.33$

$\mathrm{df}=4, F=1.455 \quad p=0.22$

df $=4, F=0.611 \quad p=0.66$

$\mathrm{df}=4, F=0.172 \quad p=0.952$

$\mathrm{df}=4, F=0.119 \quad p=0.119$

$\mathrm{df}=4, F=0.36 \quad p=0.84$

$\mathrm{df}=4, F=1.214, \quad p=0.311$

$\mathrm{df}=4, F=1.585 \quad p=0.186$

Test statistic value $=0.25$

Test statistic value $=0.21$

Test statistic value $=0.16$

Test statistic value $=0.05$
Critical value $=0.11$

Critical value $=0.11$

Critical

value $=0.12$

Critical

value $=0.12$ 
action potential firing (two cells), or after being identified as statistical outlier on all firing rate measures using a Grubb's outlier test (one cell). Additionally, cells were excluded if their input resistance was indicative of interneurons rather than pyramidal neurons (24 cells), operationally defined as cells with an input resistance of higher than 3SD above the mean.

\section{Results}

\section{Behavioral results}

To study neuronal mechanisms specifically related to contextual fear memory formation, we performed contextual FC along with a variety of control paradigms designed to control for peripheral aspects including shock exposure and exposure to a novel context (Fig. 1A). As expected, animals subjected to the full training protocol during contextual FC (four foot shocks over 10 min; FC group) froze significantly more during training ${ }^{a}$ as well as $24 \mathrm{~h}$ after training ${ }^{b}$ when reintroduced to the training context, as compared both to animals from an ISD control group and two groups of noshock controls (ISD no-shock, ISD-NS; and FC no shock, FC-NS (Fig. 1B); FC: $54.54 \pm 4.49 \%$ freezing; ISD: $14.10 \pm$ $3.83 \%$ freezing, $p<0.001$; FC-NS: $1.33 \pm 0.39 \%$ freezing, $p<0.000$; ISD-NS $\pm 2.61 \pm 1.64, p<0.000 ; n=11-16$ animals per group). Animals in the ISD group were only exposed to a single 4-s-long foot shock, which began $1 \mathrm{~s}$ after they entered the chamber, and were removed within 30 $\mathrm{s}$ following shock. As a 1-s preshock period is not considered enough time for the animals to encode the training chamber context (Fanselow, 1986), ISD animals form a weak context-shock association compared to the FC animals. This is reflected by their significantly reduced freezing on testing, which is similar to mice that were exposed to the training chamber but never received foot shocks (FC-NS).

\section{Behavioral paradigm preferentially alters excitability in RS cells in the subiculum}

We recorded from a total of 321 neurons across 54 mice [FC ( $n=75$ cells/13 animals), ISD $(n=66 / 12)$, FC-NS $(n=48 / 8)$, ISD-NS $(n=92 / 15)$, naïve $(n=43 / 6)]$. To ensure consistency with previous studies, we first assessed differences in intrinsic membrane properties between RS and BS cells in naïve animals. RS and BS cells had similar intrinsic membrane and excitability properties as reported previously (Staff et al., 2000; Graves et al., 2012), although we also found that BS neurons exhibited significantly enhanced fAHP (RS: $-1.17 \pm 0.16$ $\mathrm{mV}$, BS: $-2.88 \pm 0.36 \mathrm{mV}, p<0.001$ by independent samples $t$ test). RS and BS had similar $\mathrm{R}_{\text {input }}, \mathrm{I}_{\text {thresh }}$, mAHP and SAHP, and RMP (Table 2).

To determine whether RS and BS subicular pyramidal neurons undergo experience-dependent plasticity of intrinsic membrane properties, we next compared RMP, $R_{\text {input }}, I_{\text {thresh, }}$, and AHP (fast, medium, and slow) within each cell type across behavioral paradigms. In RS cells, we found no significant main effect of behavior on RMP $\left(\mathrm{df}=4, F=1.737, p=0.143^{\mathrm{c}} ;\right.$ Fig. $\left.2 A\right), \mathrm{R}_{\text {input }}(\mathrm{df}=4, F=$ 2.099, $p=0.082^{\text {d }}$; Fig. 2B). However, RS cells displayed significant experience-dependent changes in other intrinsic measures of excitability following behavioral para-
Table 2. Intrinsic properties of RS versus BS subicular neurons from naïve animals

\begin{tabular}{llll}
\hline & RS & BS & $p$ Value \\
RMP (mV) & $-63.6 \pm 0.71$ & $-65.4 \pm 0.67$ & 0.07 \\
$\mathrm{R}_{\text {input }}(\mathrm{MOhm})$ & $118.0 \pm 12.8$ & $94.5 \pm 5.6$ & 0.10 \\
$\mathrm{I}_{\text {thresh }}(\mathrm{pA})$ & $802.5 \pm 47.5$ & $689.5 \pm 34.5$ & 0.06 \\
fAHP $(\mathrm{mV})$ & $-1.17 \pm 0.16$ & $-2.89 \pm 0.36$ & $<0.001 * * *$ \\
mAHP $(\mathrm{mV})$ & $-4.81 \pm 0.55$ & $-4.92 \pm 0.68$ & 0.90 \\
sAHP $(\mathrm{mV})$ & $-0.61 \pm 0.07$ & $-0.47 \pm 0.06$ & 0.14 \\
& & & \\
\hline
\end{tabular}

digms. Specifically, in RS cells, we observed a significant main effect of behavioral group on both the fAHP (df $=4$, $F=2.581, p=0.038^{\circ}$; Fig. $\left.2 C, F\right)$ and $\operatorname{mAHP}(\mathrm{df}=4, F=$ 2.433, $p=0.049^{f}$; Fig. $2 D, G$ ), although there was no significant effect of behavioral group on $\mathrm{SAHP}(\mathrm{df}=4, F=$ 2.26, $p=0.064^{g}$; Fig. 2E,G). Naive animals exhibited the lowest excitability across these parameters, demonstrating that exposure to new environmental conditions or learning experiences is sufficient to remodel subicular RS neurons.

In RS cells, we did not find a significant effect of behavioral exposure on $\mathrm{I}_{\text {thresh }}\left(\mathrm{df}=4, F=1.567, p=0.18^{\mathrm{h}}\right.$; Fig. $3 A)$, nor on total spikes during a $1 \mathrm{~s}(\mathrm{df}=4, F=2.126$, $p=0.079$; Fig. $3 B$, left) current injection. In contrast, we observed a significant effect of training exposure on total spikes fired during a 15-s current injection in RS cells (df $=4, F=2.945, p=0.021$; Fig. $3 B$, right) and post hoc pairwise tests revealed a significant difference between naïve animals and all other groups (FC: $p=0.03$; ISD: $p=$ 0.02 , FC-NS: $p=0.02$; ISD-NS: $p=0.04$ ). Representative voltage responses demonstrate a similar number of spikes in naïve and FC-trained animals during a $1 \mathrm{~s}$, 350-pA current injection (Fig. 3C, left), and an increased number of spikes during a 15-s, 100-pA current injection in FC-trained animals compared to naïve animals (Fig. $3 C$, right). In general, we observed a trend toward reduced excitability on each of these measures in naiive animals compared to animals that underwent exposure to the conditioning chambers, with or without shock.

In BS cells, we observed no significant main effects of behavior on any measure of excitability (RMP: $\mathrm{df}=4, F=$ 1.166, $p=0.33^{\mathrm{k}} ; \mathrm{R}_{\text {input }}: \mathrm{df}=4, F=1.455, p=0.22^{\prime}$; fAHP: $\mathrm{df}=4, F=0.611, p=0.66^{\mathrm{m}} ; \mathrm{mAHP}: \mathrm{df}=4, F=$ $0.172, p=0.952^{\mathrm{n}} ; p=0.66$; sAHP: $\mathrm{df}=4, F=0.119, p$ $=0.975^{\circ} ; I_{\text {thresh }}: \mathrm{df}=4, F=0.36, p=0.84^{\text {; }}$; spikes during a 1-s current injection: df $=4, F=1.214, p=0.311^{q}$; spikes during a 15-s current injection: $\mathrm{df}=4, F=1.585$, $p=0.186^{r}$; Figs. 4,5$)$. This suggests $R S$ cells are relatively more responsive to environmental-induced changes, which may indicate that RS cell plasticity plays a particularly important role in regulating salient contextual information flow from the hippocampus to cortical regions.

\section{Degree of contextual learning predicts greater excitability in RS, but not BS, cells from FC animals}

Contextual fear memory acquisition and retrieval are dependent on several memory-relevant brain structures, including the hippocampus, subiculum, and entorhinal cortex, as well as fear-relevant structures such as the amygdala and mammillary bodies. The subiculum regu- 
A

RMP (RS)

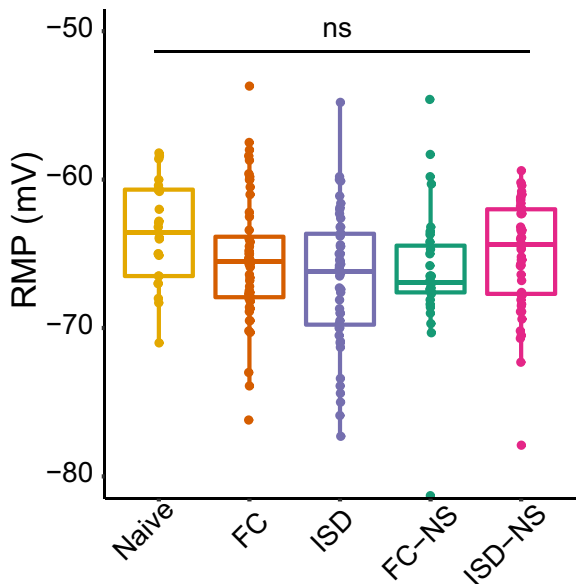

B Input resistance (RS)

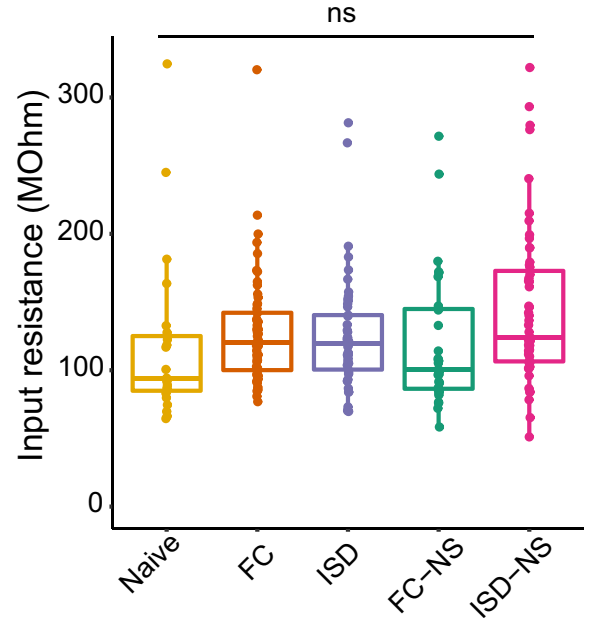

C

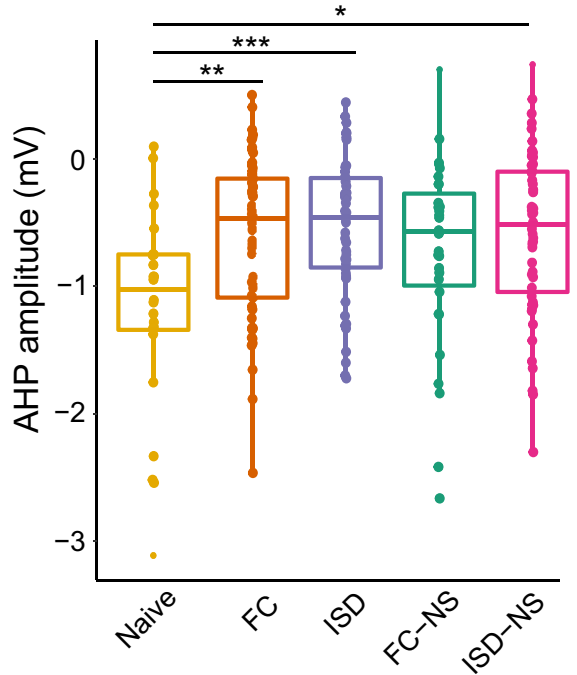

D

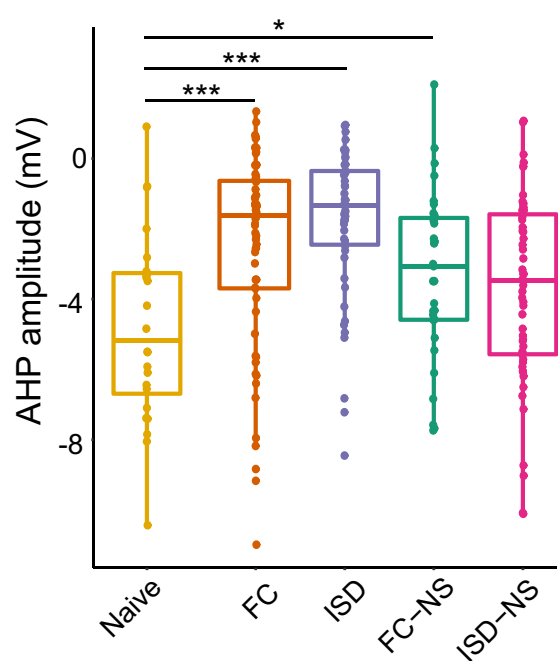

E

sAHP (RS)

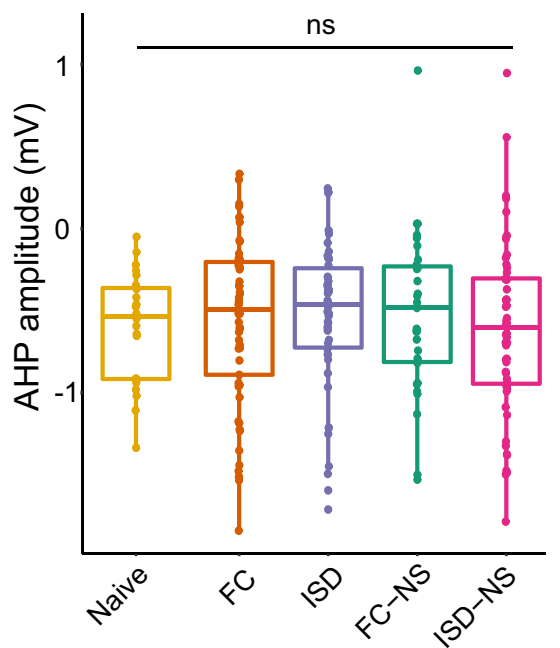

F

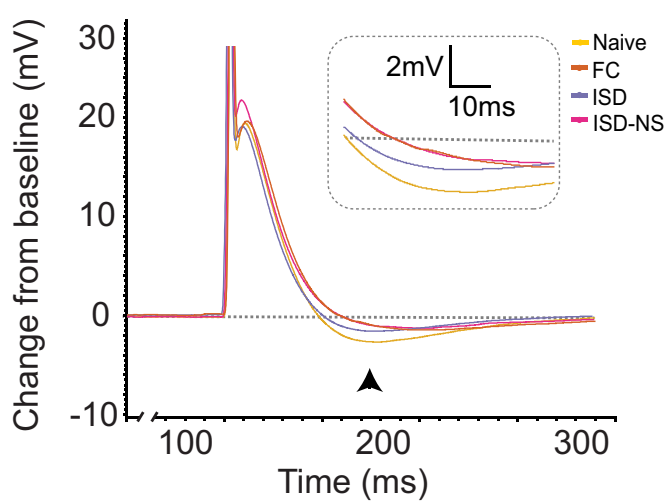

G

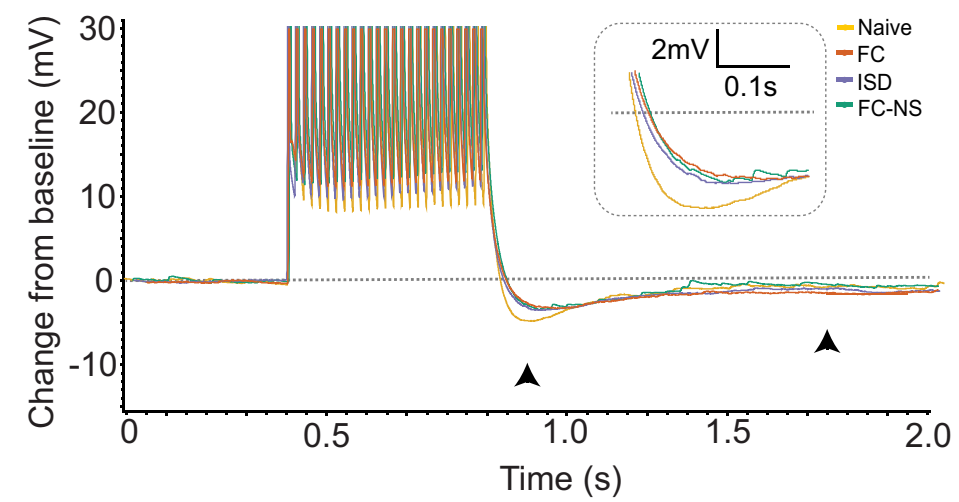

Figure 2. Exposure to behavioral training enhances excitability of neurons in RS cells as measured by post-spike and post-burst AHP. In RS cells, no significant main effect of behavior on $(\boldsymbol{A}) \mathrm{RMP}$ or $(\boldsymbol{B}) \mathrm{R}_{\text {input }}$ was observed. $\boldsymbol{C}$, However, the fAHP following an action potential elicited by a 2-ms current injection was significantly modulated by behavioral training exposure. Naïve (untrained) animals exhibited the most negative fAHP, indicating reduced excitability. $\boldsymbol{D}$, Behavioral training also reduced the post-burst (25-spike) mAHP, with naïve animals again exhibiting the most negative mAHP (least excitable). $\boldsymbol{E}$, The post-burst (25-spike) sAHP was not significantly modulated by behavioral paradigm. $\boldsymbol{F}$, Representative traces from naive, FC, and ISD animals indicate less negative fAHP (black arrowhead; inset) in FC and ISD groups. Groups with significant differences from naïve are shown. G, Representative traces from 
continued

naive, FC, and ISD animals indicate less negative mAHP (left arrowhead; inset) and unaltered sAHP (right arrowhead) in FC and ISD groups. Groups with significant differences from naïve are shown; $* p<0.05 ; * * p<0.01$, $* * * p<0.001$.

lates information transmission to each of these circuits (Roy et al., 2017). To evaluate whether greater contextual learning (i.e., more freezing during the context test following training) correlated with greater intrinsic excitability in subicular neurons in the FC group, we performed Pearson's correlation tests between all membrane properties and excitability measures of RS and BS neurons and the percentage freezing during testing (Table 3; Fig. 6A). In BS cells, degree of freezing did not significantly correlate with any membrane or excitability properties. In RS cells, freezing was significantly negatively correlated with $I_{\text {thresh }}$ in FC animals ( $r=-0.43, p=0.006 *$ ), and significantly
A $I_{\text {thresh }}(R S)$

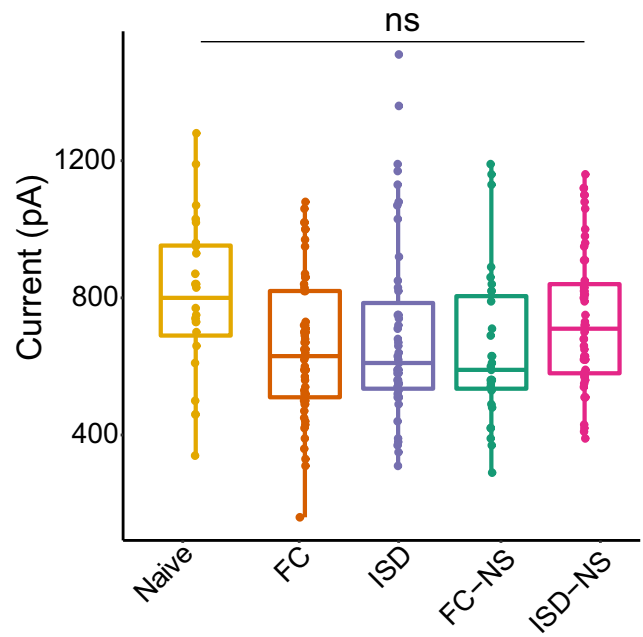

C 1s current injection
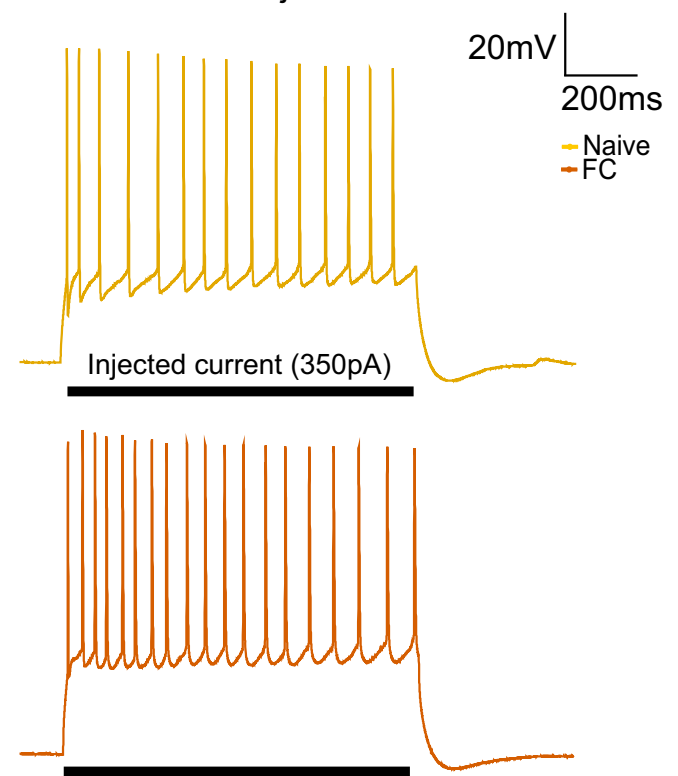

B

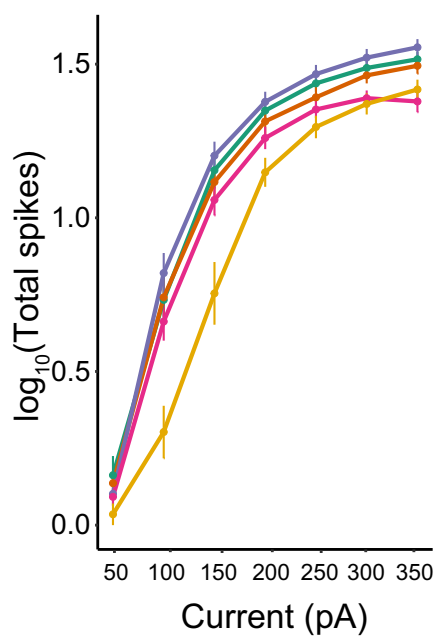

15 s current injection

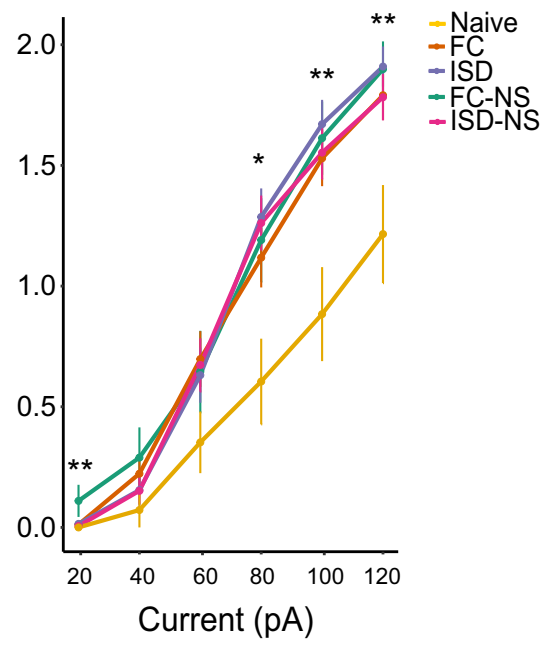

15s current injection
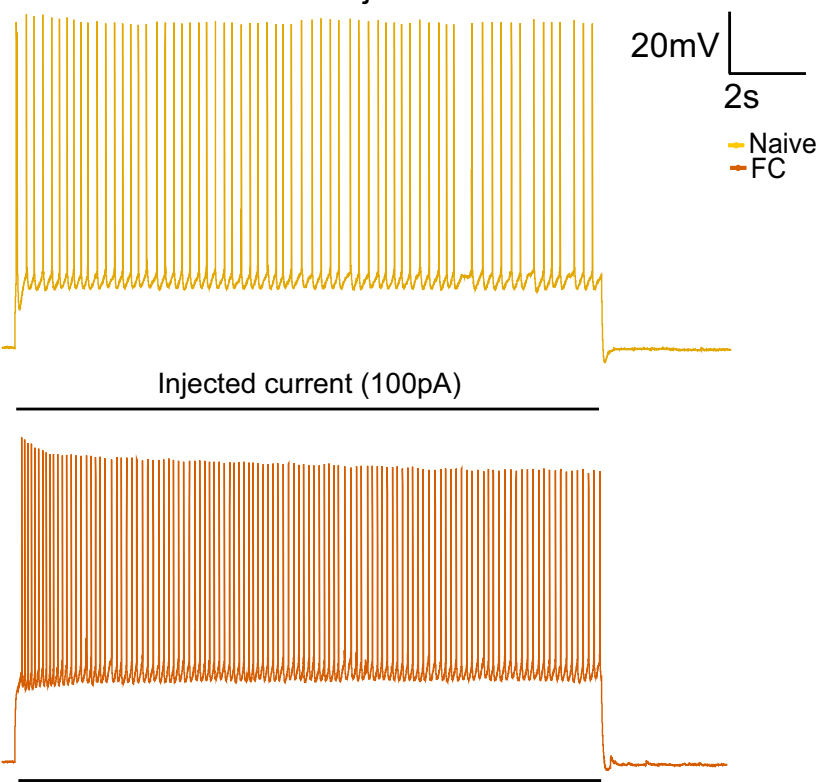

Figure 3. Behavioral training results in higher firing rate in RS cells during a 15-s current injection. $\boldsymbol{A}$, There was no main effect of behavior on $I_{\text {thresh }}$ in RS cells. B. There was a significant main effect of behavior on firing rate in response to a (right) 15-s, but not (left) 1-s, current injection of increasing amplitude, with naïve animals and displaying the fewest total spikes during the current injection paradigms. $\boldsymbol{C}$, Representative current traces from naïve and FC animals demonstrate firing rate during a 350-pA current injection (1 s) or 100-pA current injection (15 s); $* p<0.05$; **p $<0.01$; naïve, $n=24$ cells; FC, $n=61$; ISD, $n=50$; FC-NS, $n=31$; ISD-NS, $n=55$. 
A

RMP (BS)

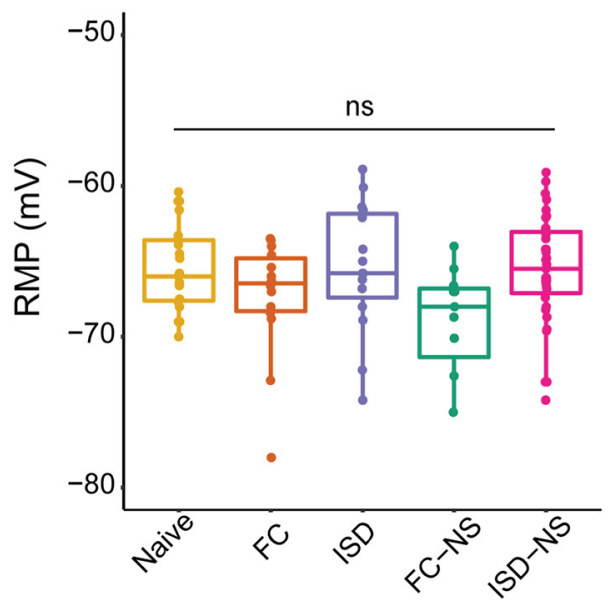

B

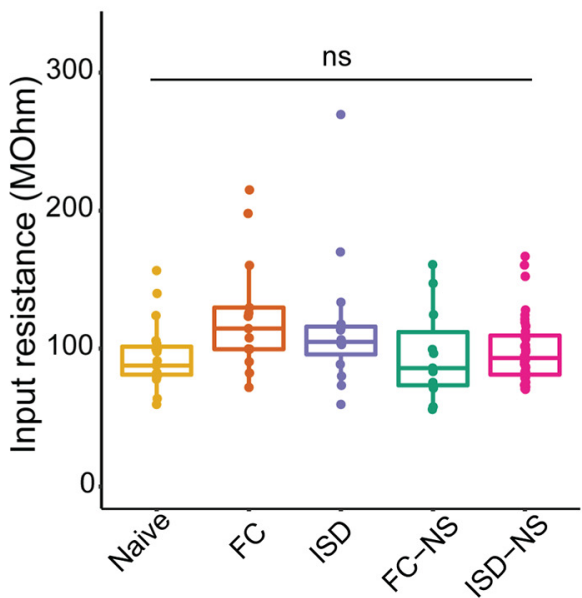

C

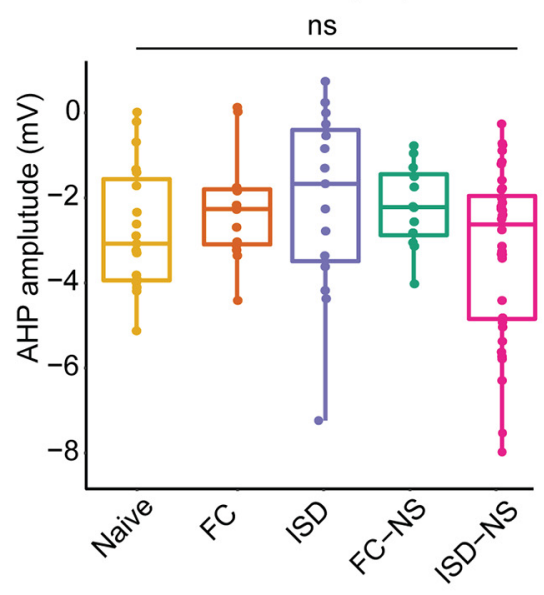

$\mathbf{F}$

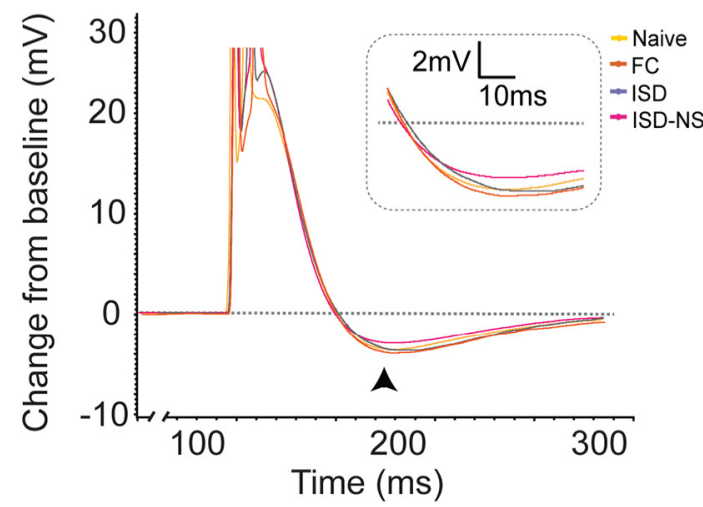

D $\quad \mathrm{mAHP}(\mathrm{BS})$

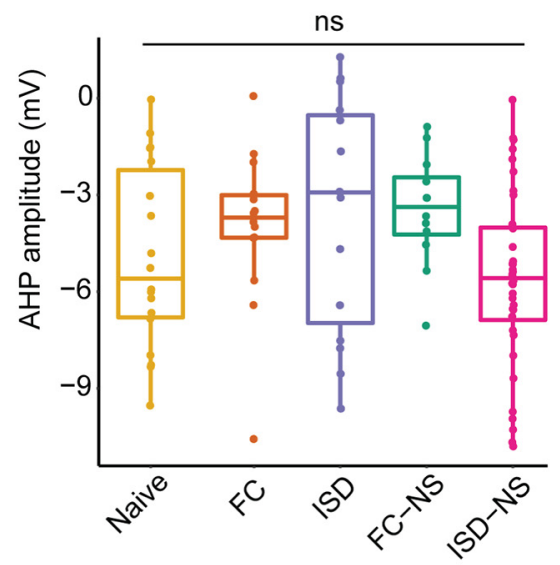

E

G
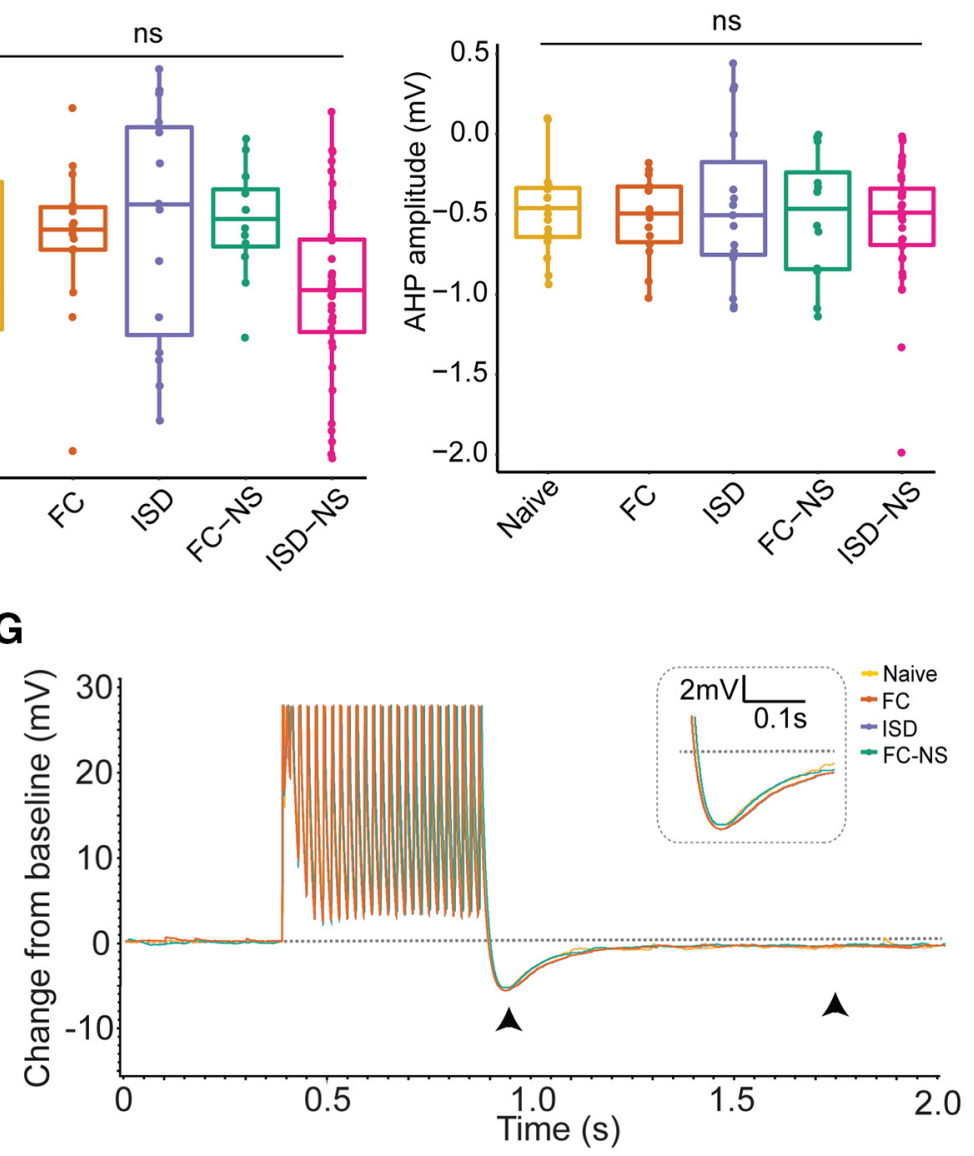

Figure 4. Exposure to behavioral training does not significantly enhance excitability of $B S$ cells. $\boldsymbol{A}, \boldsymbol{B}$, We observed no significant main effect of behavioral exposure on the RMP or $\mathrm{R}_{\text {input }}$ of BS cells. $\boldsymbol{C}$, The fAHP following an action potential elicited by a 2-ms current injection was not significantly modulated by behavioral training exposure in BS cells. $\boldsymbol{D}, \boldsymbol{E}$, Similarly, no significant main effect of behavior was observed on the post-burst (25-spike) mAHP or SAHP. $\boldsymbol{F}$, Representative traces from naive, FC, and ISD animals indicate similar fAHP (black arrowhead; inset) in naïve, FC, and ISD groups. Groups with significant differences from naïve in RS cells are included. G, Representative traces from naive, FC, and ISD animals also indicate similar mAHP (left arrowhead; inset) and SAHP (right arrowhead) in naïve, FC, and ISD groups. Groups with significant differences from naïve in RS cells are included; ns = not significant. 
A

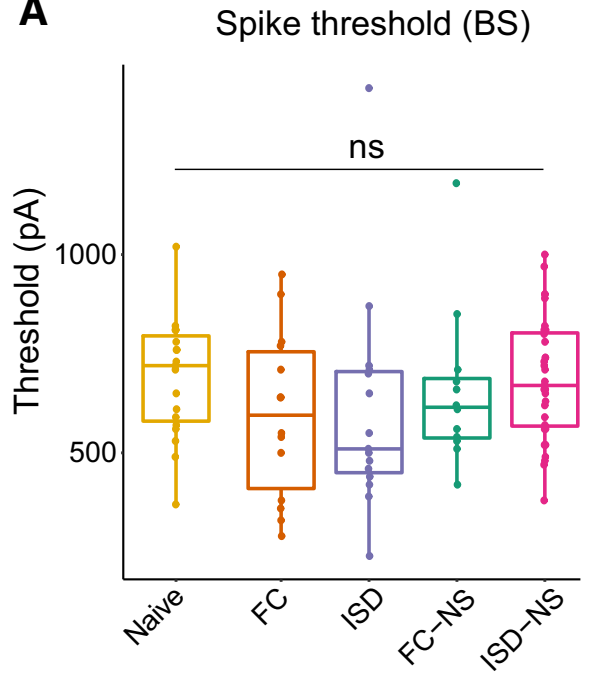

C 1s current injection
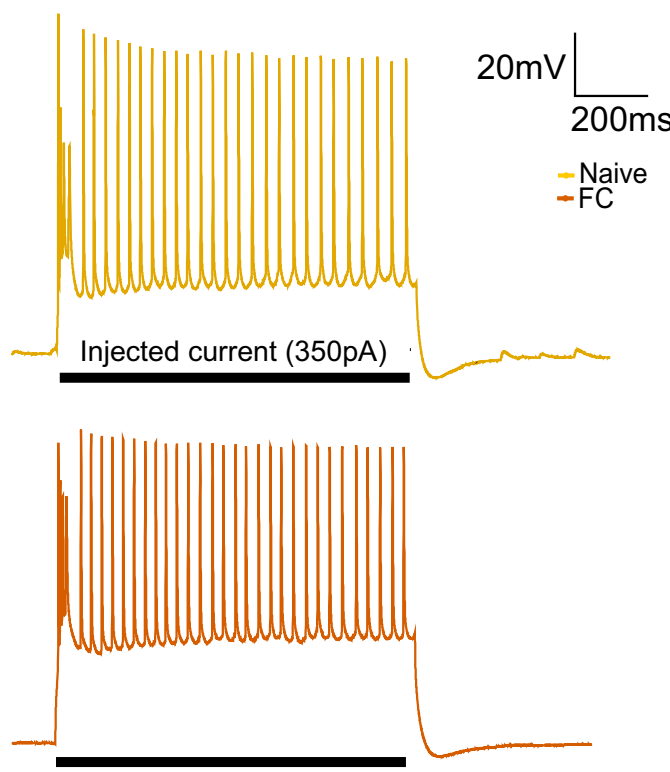

B

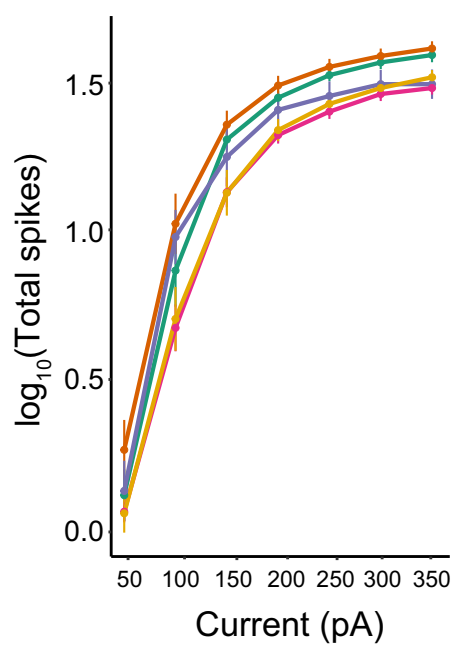

15s current injection

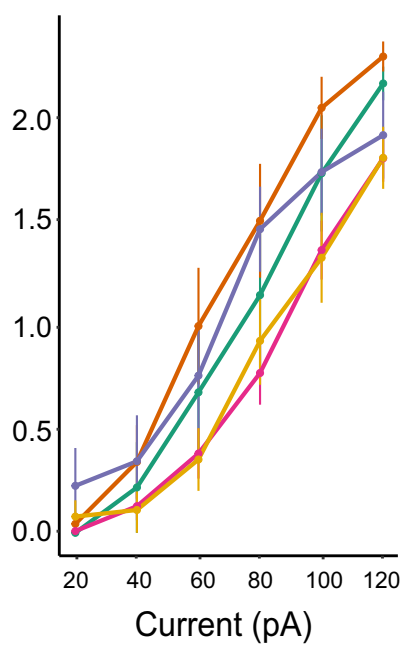

15s current injection
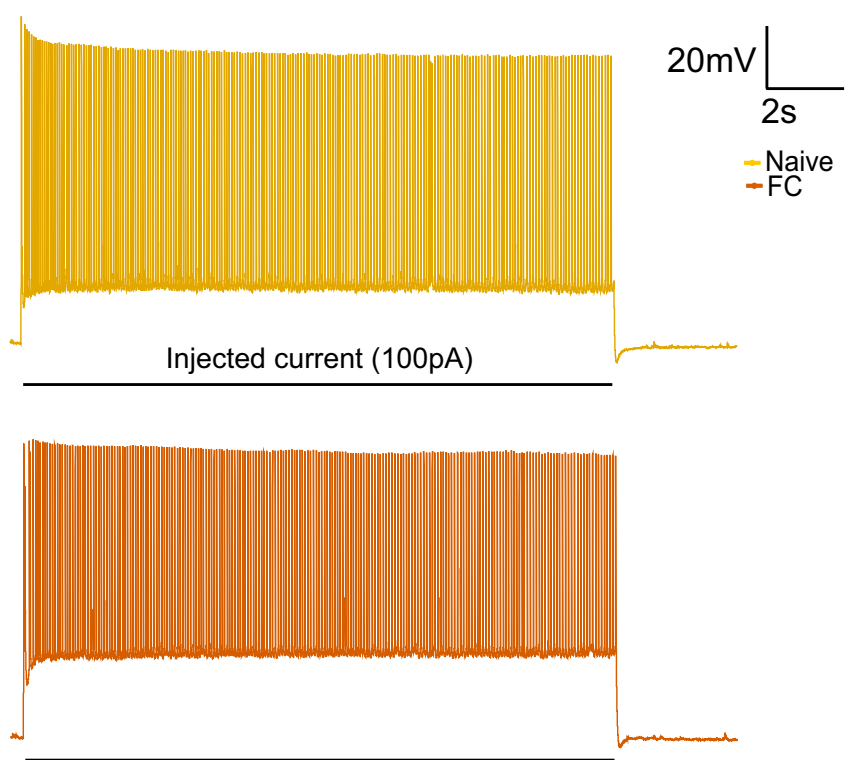

Figure 5. Behavioral training does not significantly modulate propensity to fire in BS cells. $\boldsymbol{A}$, We observed no significant main effect of behavior on $(\boldsymbol{A})$ threshold to elicit an action potential or $(\boldsymbol{B})$ firing rate in response to a 1- or 15-s current injection of increasing amplitude. $\boldsymbol{C}$, Representative current traces from naïve and FC animals demonstrate firing rate during a 350-pA current injection (1 s) or 100-pA current injection (15 s); naïve, $n=19$ cells; FC, $n=14$; ISD, $n=15$; FC-NS, $n=12$; ISD-NS, $n=36$.

positively correlated with $\mathrm{mAHP}(r=0.45, p=0.003 * ; * \alpha$ Bonferroni-adjusted to 0.0064 for multiple comparisons). This indicates that the degree of learning-induced subicular plasticity predicted contextual fear memory performance (i.e., better learning was associated with greater subicular neuron plasticity and excitability, as indicated by decreased input required to fire an action potential and quicker rebound after action potential firing as indicated by decreased $\mathrm{mAHP}$ ).

\section{Ratio of BS to RS cells in the subiculum varies with novel contextual experience}

Consistent with previous reports (Staff et al., 2000; Graves et al., 2012, 2016), nearly half of the subicular neurons recorded in brain slices from naïve mice exhibited BS firing. Surprisingly, however, when we assessed the ratio of $B S$ to $R S$ neurons in each behavioral paradigm (Fig. 6B), we found that behavioral training significantly altered the proportion of BS to RS cells. Mice in the FC group that were trained and re-exposed to the conditioning context exhibited the lowest proportion of BS cells $(18.7 \%)$, followed by the ISD group (23.1\%) and the FC-NS group $(27.9 \%)$. By a Marascuilo procedure ${ }^{\text {s }}$ (repeated $\chi^{2}$ ), this proportion was significantly different from the naîve group following each of these exposures. Among animals that underwent behavioral testing, the proportion of BS cells was highest in animals in the ISD-NS group (39.6\%); this proportion was comparable 
Table 3. Degree of contextual learning is significantly associated with greater excitability in RS but not BS cells

\begin{tabular}{lll}
\hline \multirow{2}{*}{ RMP } & $\mathrm{RS}$ & $\mathrm{BS}$ \\
& $\mathrm{R}=-0.30$ & $\mathrm{R}=-0.45$ \\
Rinput & $p=0.026$ & $p=0.11$ \\
& $\mathrm{R}=0.009$ & $\mathrm{R}=0.25$ \\
Ithresh & $p=0.945$ & $p=0.41$ \\
fAHP & $\mathrm{R}=-0.43$ & $\mathrm{R}=-0.06$ \\
& $p=0.006 *$ & $p=0.83$ \\
mAHP & $\mathrm{R}=0.03$ & $\mathrm{R}=0.12$ \\
& $p=0.64$ & $p=0.30$ \\
sAHP & $\mathrm{R}=0.37$, & $\mathrm{R}=08.45$ \\
& $p=0.003 *$ & $p=0.10$ \\
Firing (1 s) & $\mathrm{R}=0.08$ & $\mathrm{R}=0.07$ \\
Firing (15 s) & $p=0.52$ & $p=0.81$ \\
& $\mathrm{R}=0.25$, & $\mathrm{R}=0.38$ \\
& $p=0.048$ & $p=0.18$ \\
& $\mathrm{R}=0.24$ & $\mathrm{R}=0.23$ \\
& $p=0.073$ & $p=0.41$ \\
\hline
\end{tabular}

A Bonferroni correction for multiple comparisons was applied to the significance level of correlation coefficients; $* p<0.0064$.

that seen in naive animals (44.2\%). Together, these results suggest that not only does successful learning and memory on a contextual FC task robustly alter the burst firing properties of subicular pyramidal neurons, but that milder conditioning and novel environment exposure induces similar changes, although to a lesser extent (Fig. 6).

\section{Discussion}

Here, we provide the first direct evidence that subicular neurons undergo cell-type-specific learning- and experiencerelated plasticity in intrinsic properties and that this plasticity is driven both by specific enhanced excitability of RS cells and an apparent conversion of BS to RS activity.

\section{Cell-type specificity in intrinsic properties plasticity following novel context exposure and FC}

We observed general enhancement of excitability in subicular neurons following exposure to a novel context and a FC paradigm, although this differed by cell type. Specifically, we found that RS cells displayed greater plasticity in intrinsic excitability compared to BS cells, and that a greater degree of excitability in RS cells, but not BS cells, was significantly associated with a better contextual fear memory performance. Our findings are consistent with previous work showing that learning and novel environments modulate intrinsic excitability, and that the degree of learning is predictive of the magnitude of neuronal excitability changes in CA1 (Kaczorowski and Disterhoft, 2009; Matthews et al., 2009; Oh et al., 2010; Kaczorowski et al., 2011; Song et al., 2012). We demonstrate here for the first time that subicular neurons also undergo experience-dependent intrinsic plasticity and that these changes are cell-type specific.

Previous literature has shown cell-type differences in synaptic plasticity in RS and BS cells, particularly in terms of mechanisms of LTP and LTD in CA1-subicular synapses (Fidzinski et al., 2008; Moore et al., 2009; Shor et al., 2009; Graves et al., 2012, 2016). As changes in intrinsic excitability can modulate efficacy of synaptic plasticity, it is possible that our observed intrinsic plasticity is in part responsible for differences previously observed in synaptic plasticity in projections to RS and BS cells. Discrete populations of subicular cells differ in expression of various genes that likely play role in regulating intrinsic excitability, such as voltage-gated potassium and calcium channels (Cembrowski et al., 2018), which may represent potential cell-type-specific targets of neuronal

B

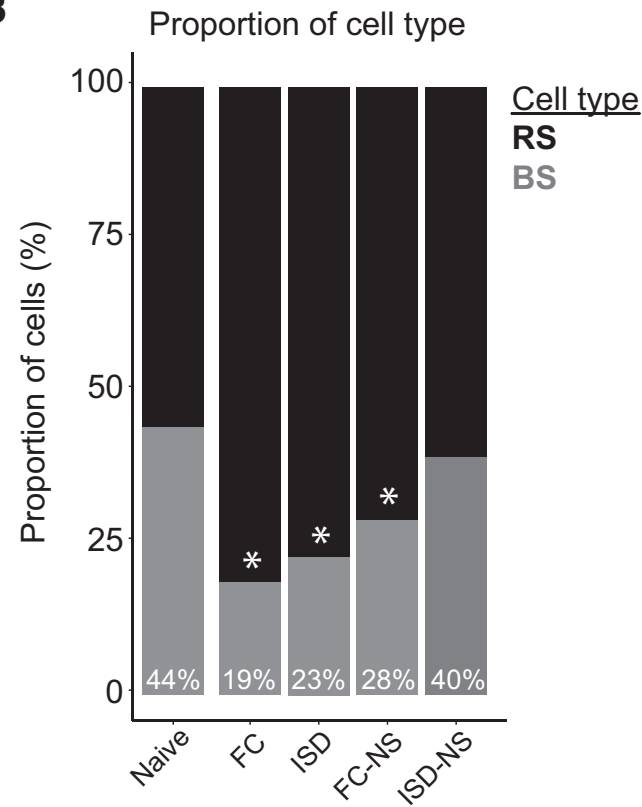

Figure 6. RS cell excitability is associated with greater learning of contextual fear memory, and contextual FC results in a reduction of BS cells. $\boldsymbol{A}$, There is a significant negative correlation between the threshold to elicit a spike in RS, but not BS, cells. B, The proportion of BS cells is decreased significantly following FC, ISD, and FC-NS exposures, with the mildest training exposure (ISD-NS) displaying a similar proportion of BS cells to naïve animals; $* p<0.05$. 
excitability modulation. Both the fAHP and mAHP are mediated by potassium and calcium currents, as well as internal calcium regulation (Storm, 1987, 1989, 1990; Brown et al., 1990). The fAHP is generated following calcium influx during the action potential, which activates large-conductance potassium channels and calcium and voltage-dependent BK currents that repolarize the cell. Similarly, the mAHP is generated following calcium influx during one or several action potentials followed by potassium and other cation efflux via SK channels, M-channels and h-channels (Gu et al., 2005; Kaczorowski, 2011; Chen et al., 2014), although the precise mechanisms have been debated and likely are not yet fully understood. The currents underlying all three AHPs are plastic and may be altered by experience and learning (Saar et al., 1998; Zhang and Linden, 2003; Matthews et al., 2008, 2009; Chen et al., 2014; Whitaker et al., 2017), although the differences in regulation of AHPs in RS versus BS cells have not been investigated. Our data suggest that regulation learning-related plasticity in the fAHP and mAHP may be cell-type dependent. Targeting intrinsic plasticity in a cell-type-specific manner in the subiculum (i.e., specifically enhancing excitability of RS cells to improve learning) may thus be an effective way to modulate cognitive function in learning- and memory-related disorders, such as dementia.

\section{Increased proportion of RS cells with novel context exposures}

Unexpectedly, we found that behavioral training resulted in a reduction in the proportion of BS cells and overrepresentation of RS cells within the subiculum. This was in a training-intensity dependent manner, where cells from animals who underwent the most intense training followed by contextual recall $(\mathrm{FC})$ had a $57 \%$ reduction in the proportion of BS cells compared to naïve animals. ISD and FC-NS also resulted in a reduction in BS:RS, albeit a more modest reduction $(47 \%$ and $36 \%$ reduction from naïve baseline, respectively). ISD-NS animals had the mildest training exposure, and showed a similar proportion of BS:RS cells to naïve animals. This suggests that fear learning and/or encoding of new contexts is facilitated by a conversion of subicular BS to RS cells, and that acute exposure to novel contexts alone, in addition to undergoing a learning paradigm, is sufficient to begin to remodel subicular neuron intrinsic properties. Because most BS cells are in the distal subiculum, we expect that this is specifically reflective of plasticity in distal subicular cells to modulate firing behavior based on context. Recent publications have demonstrated that the distal subiculum is required for spatial working memory and behavioral adaptation to context, and that the distal subiculum is specifically critical to retrieval (but not encoding) of contextual fear memories (Roy et al., 2017; Cembrowski et al., 2018). Our observation that BS cells (which are enriched in the distal subiculum) appear to convert to RS cells to the greatest degree in the FC group is consistent with the distal subiculum being preferentially involved in hippocampal-dependent spatial and contextual memory retrieval.
It is important to note that behavioral testing was randomized and electrophysiological recordings were performed by experimenters blinded to behavioral condition. Further, the sampling procedure of cells at random along the entire axis of the subiculum conforms to multiple studies by our group and others, which consistently identifies $\sim 50 \%$ BS cells in the subiculum in naïve animals (Staff et al., 2000; Jarsky et al., 2008; Graves et al., 2016). We also identified approximately half of cells as BS in naïve animals (44\%; Fig. 6), bolstering the reproducibility of these findings. Therefore, it is unlikely our findings relating specific experience-dependent changes in proportion of BS cells were confounded by oversampling of the distal subiculum.

\section{Implications and mechanisms for a change in bursting activity in the subiculum}

The observed change in the ratio of RS:BS cells within the subiculum following behavioral paradigms supports the notion that RS and BS activity convey specialized information related to learning, environmental context, and behavior. BS allows for a higher probability of signal transmission in the postsynaptic cell, and is therefore valuable in conveying information in a robust manner. However, our observation that RS cells are subject to greater plasticity following learning and novel context exposure may indicate that RS cells allow for finer-tuning of information flow that may be particularly important during active learning and retrieval, when signal transmission flexibility is crucial. Additionally, intrinsic excitability is relatively more plastic and associated with learning in RS cells, which may better poise RS cells to respond and encode information about novel experiences. Alternatively, synaptic strengthening that occurs during learning and recall may allow for a similar strength response from RS that previously required BS input, and thus RS activity may be sufficient to elicit the same effect on downstream targets after learning. Finally, it is also possible BS cells that were recruited during learning better maintain their propensity to burst, while BS cells not participating in context encoding may experience a reduction in burst propensity, thereby enhancing the signal of the remaining/ participatory BS cells over those cells that did not participate.

Previous studies have suggested that BS and RS cells are distinct populations in discrete pathways that are not interconvertible in slice preparations (Graves et al., 2012; Kim and Spruston, 2012). Additionally, transcriptional profiles are distinct between proximal and distal subicular neurons, and this distinction presumably extends to RS and BS neurons (Cembrowski et al., 2018). Recent work has suggested, however, that there is collateralization of projections that may indicate a greater degree of diversity and potential for flexibility in projection targets from RS and BS cells than previously thought (Cembrowski et al., 2018). The ability to burst also seems to be an intrinsic property of all subicular neurons primarily mediated by calcium currents via R-type and T-type calcium channels that open during depolarization to allow calcium influx (Jung et al., 2001; Su et al., 2002; Yue and Yaari, 2004), 
and bursting is sensitive to changes in potassium currents (Jensen et al., 1994; Staff et al., 2000; Hu et al., 2017). This suggests that a remodeling of ion channel populations and activity in vivo during learning or novel context exposure may be a candidate mechanism for changes in bursting activity in the subiculum. Age and status epilepticus have also been shown to change proportion of BS versus RS in the subiculum (Wellmer et al., 2002; Knopp et al., 2005; Chung et al., 2015), and other evidence suggests that such activity-dependent changes in bursting activity are mediated by T-type calcium channels (Su et al., 2002).

Previous work has demonstrated cell-type-specific modulation of both intrinsic and synaptic plasticity in the subiculum (Moore et al., 2009; Graves et al., 2012, 2016). Specifically, bath application of BDNF enhances intrinsic excitability of BS neurons while reducing excitability of RS neurons (Graves et al., 2016). Similarly, glutamatergic and cholinergic inputs bidirectionally modulate excitability depending on cell type and input composition, with cholinergic and glutamatergic inputs acting synergistically to enhance bursting in BS neurons but glutamatergic signaling via mGluR5 acting to suppress bursting in BS cells in the absence of concurrent cholinergic inputs (Moore et al., 2009; Graves et al., 2012). In addition to their role in mediating burst propensity, mGluR5 activation also results in reduction of the AHP and enhances intrinsic excitability of cortical RS neurons (Sourdet et al., 2003). These studies were completed exclusively in behaviorally naive rodents, however, and it is unclear how learning and memory formation in vivo may involve these processes. Based on these previous models, it is possible that circuitry activation during learning and memory recall preferentially induces signaling via mGluR5 receptors to suppress bursting in BS cells and facilitate excitability of RS cells/RS activity. mGluR5 activation is critical to learning and memory, with genetic knockout and pharmacological antagonism of mGluR5 impairing performance on hippocampal-dependent spatial learning and memory tasks (Xu et al., 2009; Simonyi et al., 2010). Conversely, enhancement of mGluR5 signaling via a specific positive allosteric modulator enhances performance on contextual FC specifically (Sethna and Wang, 2014). Together with our data, this suggests that in addition to ion channel composition, possible mGluR5-mediated enhancement of $\mathrm{RS}$ activity in the subiculum is important for regulating hippocampal output in learning and memory. Future studies may investigate changes in ion channel density and mGluR5 signaling in the subiculum following learning, to account for the observed flexibility in RS versus BS signaling following learning in vivo.

Because we observed a concurrent enhancement of intrinsic excitability and reduction in burst firing following FC and novel context exposure, it is likely that measures of intrinsic excitability and propensity to burst are two forms of plasticity that may be regulated separately. Indeed, burst propensity and other measures of intrinsic excitability are distinctly governed, which may allow for finer-tuning of neuronal remodeling in the subiculum following learning and novel context exposure.

\section{Plasticity within the cubiculum regulates spatial information output from the hippocampus}

In conclusion, we demonstrate here for the first time that subicular neurons undergo cell-type-specific plasticity in intrinsic excitability following learning and novel context exposure. Interestingly, an unexpected additional form of plasticity appears to be a change in ratio of BS:RS cells following behavioral training, and memory consolidation and recall. The ability of the subiculum to regulate hippocampal output via an increase or decrease in BS:RS activity in vivo following learning likely represents a novel form of plasticity not previously observed in slice preparations that provides further insight to our understanding of the precise role of the subiculum in learning and memory.

\section{References}

Behr J, Wozny C, Fidzinski P, Schmitz D (2009) Synaptic plasticity in the subiculum. Prog Neurobiol 89:334-342. CrossRef Medline

Brown DA, Gähwiler BH, Griffith WH, Halliwell JV (1990) Membrane currents in hippocampal neurons. Prog Brain Res 83:141-160. Medline

Carlesimo GA, Piras F, Orfei MD, lorio M, Caltagirone C, Spalletta G (2015) Atrophy of presubiculum and subiculum is the earliest hippocampal anatomical marker of Alzheimer's disease. Alzheimers Dement (Amst) 1:24-32. CrossRef Medline

Cembrowski MS, Phillips MG, DiLisio SF, Shields BC, Winnubst J, Chandrashekar J, Bas E, Spruston N (2018) Dissociable structural and functional hippocampal outputs via distinct subiculum cell classes. Cell 173:1280-1292.e18. CrossRef Medline

Chen S, Benninger F, Yaari Y (2014) Role of small conductance $\mathrm{Ca}^{2+}$-activated $\mathrm{K}(+)$ channels in controlling $\mathrm{CA} 1$ pyramidal cell excitability. J Neurosci 34:8219-8230. CrossRef Medline

Chung S, Spruston N, Koh S (2015) Age-dependent changes in intrinsic neuronal excitability in subiculum after status epilepticus. PLoS One 10:e0119411. CrossRef Medline

Fanselow MS (1986) Associative vs topographical accounts of the immediate shock-freezing deficit in rats: implications for the response selection rules governing species-specific defensive reactions. Learn Motiv 17:16-39. CrossRef

Faul F, Erdfelder E, Lang A-G, Buchner A (2007) G*Power 3: a flexible statistical power analysis program for the social, behavioral, and biomedical sciences. Behav Res Methods 39:175-191. Medline

Fidzinski P, Shor OL, Behr J (2008) Target-cell-specific bidirectional synaptic plasticity at hippocampal output synapses. Eur J Neurosci 27:1111-1118. CrossRef Medline

Gabrieli JDE, Brewer JB, Desmond JE, Glover GH (1997) Separate neural bases of two fundamental memory processes in the human medial temporal lobe. Science 276:264-266. CrossRef Medline

Graves AR, Moore SJ, Bloss EB, Mensh BD, Kath WL, Spruston N (2012) Hippocampal pyramidal neurons comprise two distinct cell types that are countermodulated by metabotropic receptors. Neuron 76:776-789. CrossRef Medline

Graves AR, Moore SJ, Spruston N, Tryba AK, Kaczorowski CC (2016) Brain-derived neurotrophic factor differentially modulates excitability of two classes of hippocampal output neurons. J Neurophysiol 116:466-471. CrossRef Medline

Gu N, Vervaeke K, Hu H, Storm JF (2005) Kv7/KCNQ/M and HCN/h, but not $\mathrm{KCa} 2 / \mathrm{SK}$ channels, contribute to the somatic medium after-hyperpolarization and excitability control in CA1 hippocampal pyramidal cells. J Physiol 566:689-715. CrossRef Medline

Haukvik UK, Westlye LT, Mørch-Johnsen L, Jørgensen KN, Lange EH, Dale AM, Melle I, Andreassen OA, Agartz I (2015) In vivo hippocampal subfield volumes in schizophrenia and bipolar disorder. Biol Psychiatry 77:581-588. CrossRef Medline 
Hodgetts CJ, Voets NL, Thomas AG, Clare S, Lawrence AD, Graham KS (2017) Ultra-high-field fMRI reveals a role for the subiculum in scene perceptual discrimination. J Neurosci 37:3150-3159. CrossRef Medline

Honda Y, Ishizuka N (2015) Topographic distribution of cortical projection cells in the rat subiculum. Neurosci Res 92:1-20. CrossRef Medline

Hu B, Cilz NI, Lei S (2017) Somatostatin depresses the excitability of subicular bursting cells: roles of inward rectifier $\mathrm{K}+$ channels, KCNQ channels and Epac. Hippocampus 27:971-984. CrossRef Medline

Ishihara Y, Fukuda T (2016) Immunohistochemical investigation of the internal structure of the mouse subiculum. Neuroscience 337: 242-266. CrossRef Medline

Jarsky T, Mady R, Kennedy B, Spruston N (2008) Distribution of bursting neurons in the CA1 region and the subiculum of the rat hippocampus. J Comp Neurol 506:535-547. CrossRef Medline

Jensen MS, Azouz R, Yaari Y (1994) Variant firing patterns in rat hippocampal pyramidal cells modulated by extracellular potassium. J Neurophysiol 71:831-839. CrossRef Medline

Jung HY, Staff NP, Spruston N (2001) Action potential bursting in subicular pyramidal neurons is driven by a calcium tail current. J Neurosci 21:3312-3321. CrossRef Medline

Kaczorowski CC (2011) Bidirectional pattern-specific plasticity of the slow afterhyperpolarization in rats: role for high-voltage activated Ca2 + channels and I h. Eur J Neurosci 34:1756-1765. CrossRef Medline

Kaczorowski CC, Disterhoft JF (2009) Memory deficits are associated with impaired ability to modulate neuronal excitability in middle-aged mice. Learn Mem 16:362-366. CrossRef Medline

Kaczorowski CC, Disterhoft J, Spruston N (2007) Stability and plasticity of intrinsic membrane properties in hippocampal CA1 pyramidal neurons: effects of internal anions. J Physiol 578:799-818. CrossRef Medline

Kaczorowski CC, Sametsky E, Shah S, Vassar R, Disterhoft JF (2011) Mechanisms underlying basal and learning-related intrinsic excitability in a mouse model of Alzheimer's disease. Neurobiol Aging 32:1452-1465. CrossRef Medline

Kim Y, Spruston N (2012) Target-specific output patterns are predicted by the distribution of regular-spiking and bursting pyramidal neurons in the subiculum. Hippocampus 22:693-706. CrossRef Medline

Knopp A, Kivi A, Wozny C, Heinemann U, Behr J (2005) Cellular and network properties of the subiculum in the pilocarpine model of temporal lobe epilepsy. J Comp Neurol 483:476-488. CrossRef Medline

Kumar A, Foster T (2007) Environmental enrichment decreases the after hyperpolarization in senescent rats. Brain Res 1130:103-107. CrossRef Medline

Lindberg O, Mårtensson G, Stomrud E, Palmqvist S, Wahlund LO, Westman E, Hansson O (2017) Atrophy of the posterior subiculum is associated with memory impairment, tau- and $A \beta$ pathology in non-demented individuals. Front Aging Neurosci 9:306. CrossRef Medline

Maren S (1999) Neurotoxic or electrolytic lesions of the ventral subiculum produce deficits in the acquisition and expression of Pavlovian fear conditioning in rats. Behav Neurosci 113:283-290. Medline

Matthews EA, Weible AP, Shah S, Disterhoft JF (2008) The BKmediated $\mathrm{fAHP}$ is modulated by learning a hippocampusdependent task. Proc Natl Acad Sci USA 105:15154-15159. CrossRef Medline

Matthews EA, Linardakis JM, Disterhoft JF (2009) The fast and slow afterhyperpolarizations are differentially modulated in hippocampal neurons by aging and learning. J Neurosci 29:4750-4755. CrossRef Medline

Moore SJ, Cooper DC, Spruston N (2009) Plasticity of burst firing induced by synergistic activation of metabotropic glutamate and acetylcholine receptors. Neuron 61:287-300. CrossRef Medline
Naber PA, Witter MP (1998) Subicular efferents are organized mostly as parallel projections: a double-labeling, retrograde-tracing study in the rat. J Comp Neurol 393:284-297. CrossRef Medline

Neuner SM, Wilmott LA, Hope KA, Hoffmann B, Chong JA, Abramowitz J, Birnbaumer L, O'Connell KM, Tryba AK, Greene AS, Chan CS, Kaczorowski CC (2015) TRPC3 channels critically regulate hippocampal excitability and contextual fear memory. Behav Brain Res 281:69-77. CrossRef

O'Mara SM (2005) The subiculum: what it does, what it might do, and what neuroanatomy has yet to tell us. J Anat 207:271-282. CrossRef Medline

O’Mara SM, Sanchez-Vives MV, Brotons-Mas JR, O'Hare E (2009) Roles for the subiculum in spatial information processing, memory, motivation and the temporal control of behaviour. Prog Neuropsychopharmacol Biol Psychiatry 33:782-790. CrossRef Medline

Oh MM, Mckay BM, Power JM, Disterhoft JF (2009) Learning-related postburst afterhyperpolarization reduction in CA1 pyramidal neurons is mediated by protein kinase A. Proc Natl Acad Sci USA 106:1620-1625. CrossRef Medline

Oh MM, Oliveira FA, Disterhoft JF (2010) Learning and aging related changes in intrinsic neuronal excitability. Front Aging Neurosci 2:2. CrossRef Medline

Phillips RG, LeDoux JE (1992) Differential contribution of amygdala and hippocampus to cued and contextual fear conditioning. Behav Neurosci 106:274-285. Medline

Roy DS, Kitamura T, Okuyama T, Ogawa SK, Sun C, Obata Y, Yoshiki A, Tonegawa S (2017) Distinct neural circuits for the formation and retrieval of episodic memories. Cell 170:10001012.e19. CrossRef Medline

Saar D, Grossman Y, Barkai E (1998) Reduced after-hyperpolarization in rat piriform cortex pyramidal neurons is associated with increased learning capability during operant conditioning. Eur J Neurosci 10:1518-1523. Medline

Sehgal M, Ehlers VL, Moyer JR Jr (2014) Learning enhances intrinsic excitability in a subset of lateral amygdala neurons. Learn Mem 21:161-170. CrossRef Medline

Sehgal M, Song C, Ehlers VL, Moyer JR Jr (2013) Learning to learn intrinsic plasticity as a metaplasticity mechanism for memory formation. Neurobiol Learn Mem 105:186-199. CrossRef Medline

Sethna F, Wang H (2014) Pharmacological enhancement of mGluR5 facilitates contextual fear memory extinction. Learn Mem 21:647650. CrossRef Medline

Shor OL, Fidzinski P, Behr J (2009) Muscarinic acetylcholine receptors and voltage-gated calcium channels contribute to bidirectional synaptic plasticity at CA1-subiculum synapses. Neurosci Lett 449:220-223. CrossRef Medline

Simonyi A, Schachtman TR, Christoffersen GR (2010) Metabotropic glutamate receptor subtype 5 antagonism in learning and memory. Eur J Pharmacol 639:17-25. CrossRef Medline

Soler-Cedeño O, Cruz E, Criado-Marrero M, Porter JT (2016) Contextual fear conditioning depresses infralimbic excitability. Neurobiol Learn Mem 130:77-82. CrossRef Medline

Song C, Detert JA, Sehgal M, Moyer JR Jr (2012) Trace fear conditioning enhances synaptic and intrinsic plasticity in rat hippocampus. J Neurophysiol 107:3397-3408. CrossRef Medline

Song C, Ehlers VL, Moyer JR Jr (2015) Trace fear conditioning differentially modulates intrinsic excitability of medial prefrontal cortex-basolateral complex of amygdala projection neurons in infralimbic and prelimbic cortices. J Neurosci 35:13511-13524. CrossRef Medline

Sourdet V, Russier M, Daoudal G, Ankri N, Debanne D (2003) Longterm enhancement of neuronal excitability and temporal fidelity mediated by metabotropic glutamate receptor subtype 5 . J Neurosci 23:10238-10248. Medline

Staff NP, Jung HY, Thiagarajan T, Yao M, Spruston N (2000) Resting and active properties of pyramidal neurons in subiculum and CA1 of rat hippocampus. J Neurophysiol 84:2398-2408. CrossRef Medline 
Storm JF (1987) Action potential repolarization and a fast afterhyperpolarization in rat hippocampal pyramidal cells. J Physiol 385:733-759. CrossRef Medline

Storm JF (1989) An after-hyperpolarization of medium duration in rat hippocampal pyramidal cells. J Physiol 409:171-190. Medline

Storm JF (1990) Potassium currents in hippocampal pyramidal cells. Prog Brain Res 83:161-187. Medline

Su H, Sochivko D, Becker A, Chen J, Jiang Y, Yaari Y, Beck H (2002) Upregulation of a $\mathrm{T}$-type $\mathrm{Ca} 2+$ channel causes a long-lasting modification of neuronal firing mode after status epilepticus. $J$ Neurosci 22:3645-3655. Medline

Tang H, Wu GS, Xie J, He X, Deng K, Wang H, Xu F, Luo HR (2016) Brain-wide map of projections from mice ventral subiculum. Neurosci Lett 629:171-179. CrossRef Medline

Titley HK, Brunel N, Hansel C (2017) Toward a neurocentric view of learning. Neuron 95:19-32. CrossRef Medline

Wellmer J, Su H, Beck H, Yaari Y (2002) Long-lasting modification of intrinsic discharge properties in subicular neurons following status epilepticus. Eur J Neurosci 16:259-266. Medline
Whitaker LR, Warren BL, Venniro M, Harte TC, McPherson KB, Beidel J, Bossert JM, Shaham Y, Bonci A, Hope BT (2017) Bidirectional modulation of intrinsic excitability in rat prelimbic cortex neuronal ensembles and non-ensembles after operant learning. $J$ Neurosci 37:8845-8856. CrossRef Medline

Wozny C, Maier N, Schmitz D, Behr J (2008) Two different forms of long-term potentiation at CA1-subiculum synapses. J Physiol 586: 2725-2734. CrossRef Medline

Xu J, Zhu Y, Contractor A, Heinemann SF (2009) mGluR5 has a critical role in inhibitory learning. J Neurosci 29:3676-3684. CrossRef Medline

Yue C, Yaari Y (2004) KCNQ/M channels control spike afterdepolarization and burst generation in hippocampal neurons. J Neurosci 24:4614-4624. CrossRef Medline

Zammit AR, Ezzati A, Zimmerman ME, Lipton RB, Lipton ML, Katz MJ (2017) Roles of hippocampal subfields in verbal and visual episodic memory. Behav Brain Res 317:157-162. CrossRef Medline

Zhang W, Linden DJ (2003) The other side of the engram: experience-driven changes in neuronal intrinsic excitability. Nat Rev Neurosci 4:885-900. CrossRef Medline 